\title{
A NEOTERIC ROOT COVERAGE TECHNIQUE- BRIDGE FLAP
}

\author{
Veenadharini Gundapaneni', Shivaprasad B. M², Nehal Singhani $^{3}$
}

${ }_{1}^{1}$ Senior Lecturer, Department of Periodontology, St. Joseph Dental College \& Hospital, Eluru, Andhra Pradesh. 2 Professor, Department of Periodontology, Rajarajeswari Dental College \& Hospital, Bangalore, Karnataka.

3MDS, Department of Periodontology, Rajarajeswari Dental College and Hospital, Bangalore, Karnataka.

HOW TO CITE THIS ARTICLE: Gundapaneni V, Shivaprasad BM, Singhani N. A neoteric root coverage technique- bridge flap. J. Evolution Med. Dent. Sci. 2018;7(15):1932-1935, DOI: 10.14260/jemds/2018/435

\section{PRESENTATION OF CASE}

Two systemically healthy non-smoker patients visited the Department of Periodontology, Rajarajeswari Dental College and Hospital, Bangalore, India, with the chief complaint of receding gums in the lower anteriors. Clinical examination revealed an inadequate zone of Attached Gingiva (AG) with either shallow vestibule or aberrant frenum attachment in both the cases. The general description and the clinical parameters of the patients are provided in Table No. 1. Clinical parameters were recorded using UNC-15 periodontal probe at baseline and at 3 months post-surgically, which included probing pocket depth (PPD- distance from gingival margin to base of pocket), GR (distance from cemento-enamel junction to gingival margin), width of $A G$ (distance from base of pocket to mucogingival junction) and clinical attachment level (CAL- distance from cemento-enamel junction to base of pocket) as shown in Table 1. The procedure was well explained to the patient and informed consent was obtained for surgery.

Root coverage has become an imperative aspect of periodontal plastic surgery and is being achieved by a wide variety of surgical techniques. These surgical solutions, although carry their own merits pose certain difficulties, that is their inadequacy to treat other aetiological entities simultaneously with recession. The present case series reports the efficiency of bridge flap technique as a single-step surgical procedure for increasing the depth of the vestibule, covering the denuded root surfaces, increasing the width of the attached gingiva (AG) and relieving the abnormal frenal pull. This article reports two case reports, in which bridge flap technique has been used as a sole procedure for root coverage. The bridge flap technique can be an effective singlestep solution for the mucogingival problems, as it offers considerable advantages over other surgical techniques in terms of simplicity, limited chair-side time and single surgical intervention. In the present case series, the treated cases demonstrated adequate increase in width of the attached gingiva.

In the recent past, dentistry has progressed in such a way that clinicians are not only entailed to treat the disease and recuperate function, but also are working towards pursuing the aesthetic satisfaction of patients. With a view of achieving a contenting smile for their patients, dentists must not only

'Financial or Other Competing Interest': None.

Submission 22-02-2018, Peer Review 23-03-2018,

Acceptance 28-03-2018, Published 09-04-2018.

Corresponding Author:

Dr. Veenadharini Gundapaneni,

Department of Periodontology,

Rajarajeswari Dental College and Hospital,

Bangalore, Karnataka.

E-mail: gvdharini@gmail.com

DOI: $10.14260 /$ jemds $/ 2018 / 435$ consider white aesthetics, but also attention for pink aesthetics is needed as it plays a fundamental role in instituting an ideal smile.

Gingival recession (GR) in multiple anterior teeth is a common concern either due to aesthetic considerations or root sensitivity.(1) Gingival recession occurs when the location of the gingival margin lies apical to the cementoenamel junction (CEJ), leading to exposure of the root surface resulting in mucogingival problems. These are usually characterised by gingival inflammation in an area of limited or no attached tissue.(2)

Recession due to periodontitis may involve any of the tooth surfaces and is irreversible, whereas facial recession due to mechanical factors is most of the times reversible or partially reversible with periodontal reconstructive procedures.(3) It has been estimated that over $60 \%$ of the population has at least one such buccal recession defect and that such defects are predominantly seen in patients with good oral hygiene.(4)

Regardless of the reason for treatment, the objectives should aim to cover denuded root surfaces, increase the width and buccolingual thickness of the attached tissue and to establish a proper vestibular depth.(5) Numerous surgical procedures like the coronally advanced flap, lateral pedicle flap, free gingival graft and connective tissue graft techniques have then been enumerated by various clinicians for these aforementioned mucogingival entities. These surgical solutions, although carry their own merits, pose certain difficulties, that is their inadequacy to treat other aetiological entities simultaneously with recession.(6)

The common requirement for all these procedures is the presence of an adequate width of attached gingiva. In many cases wherein the width of attached gingiva is inadequate, a variety of techniques like vestibuloplasty, free gingival grafting are performed prior to root coverage procedures to augment the width of attached gingiva, which either involve a second appointment or a secondary surgical site which is very exasperating for both patient and the dentist.(7) Therefore, a newer technique which was first proposed by Marggraf( ${ }^{(8)}$ with a single step solution to cover the denuded root surface as well as to augment the width of attached gingiva is adopted in the present case series. With this technique the two surgical procedures are combined in a single technique to cover multiple recessions in anterior region and simultaneously to increase the width of attached gingiva and eliminate the aetiological factors.

\section{Procedure}

Local anaesthesia $(2 \%$ lignocaine hydrochloride with $1: 80,000$ epinephrine) was administered prior to the procedure. The surgical procedure included the bridge flap technique as introduced by $\operatorname{Marggraf(}^{(8)}$ and later on modified by Romanos.(9) This technique included an arch-shaped 
incision in the vestibule at approximately $2 \times \mathrm{GR}+2 \mathrm{~mm}$ from the gingival margin.(6) A spilt-thickness flap was elevated in the apico-coronal direction by making a sulcular incision, connecting it with the first incision so that the whole bridge flap could be elevated and repositioned coronally to cover the denuded root surfaces. No vertical incisions were given. This forms a bridge from coronal aspect to the vestibule. Thereafter, root conditioning was done with ethylene diamine tetraacetic acid. The whole bridge flap was coronally positioned and pressed towards the alveolar bone for at least 3 minutes to avoid haematoma formation. Then, the flap was repositioned coronally with interrupted sutures and periodontal dressing was placed. Post-surgical instructions and medications (ibuprofen $400 \mathrm{mg}$ thrice daily) were given for 5 days to avoid post-operative pain and swelling. The patients were instructed to use a soft toothbrush for mechanical plaque control in the surgical area by a coronally directed roll technique. Patient was recalled after 10 days for suture removal.

Case I

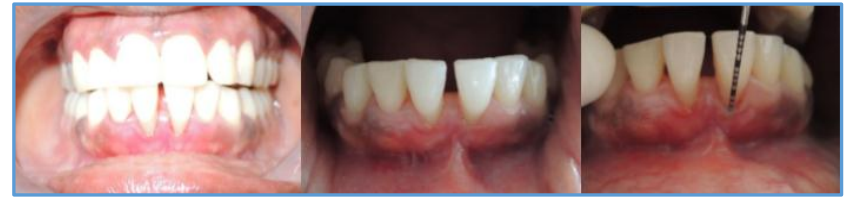

Figure 1. Preoperative Photographs showing Inadequate Width of the attached Gingiva and Miller Class III Recession with Diastema IRT 3141

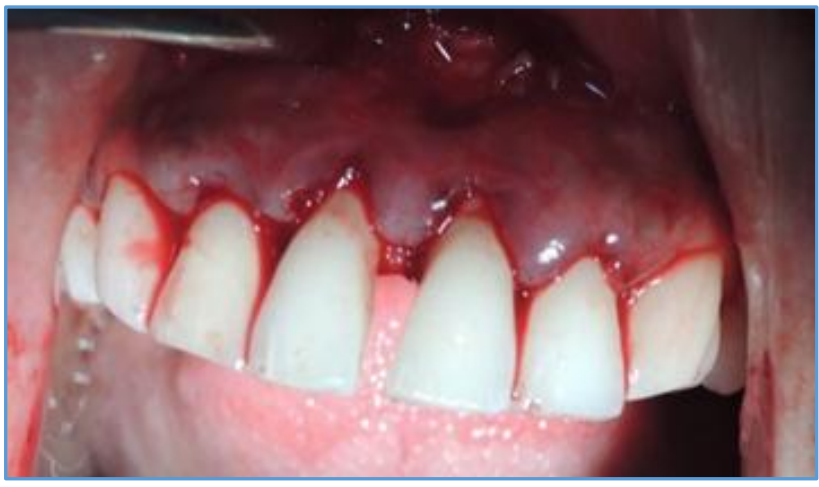

Figure 2. Sulcular and Vestibular Incisions Placed

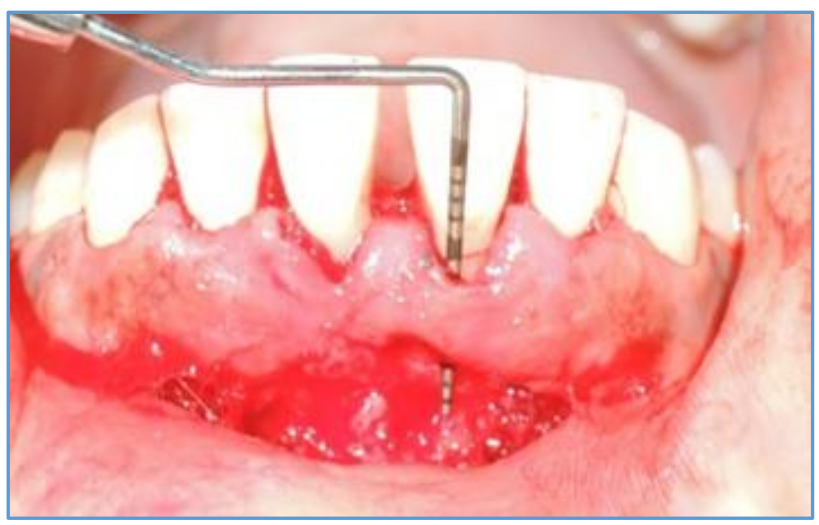

Figure 3. Partial Thickness Flap Raised

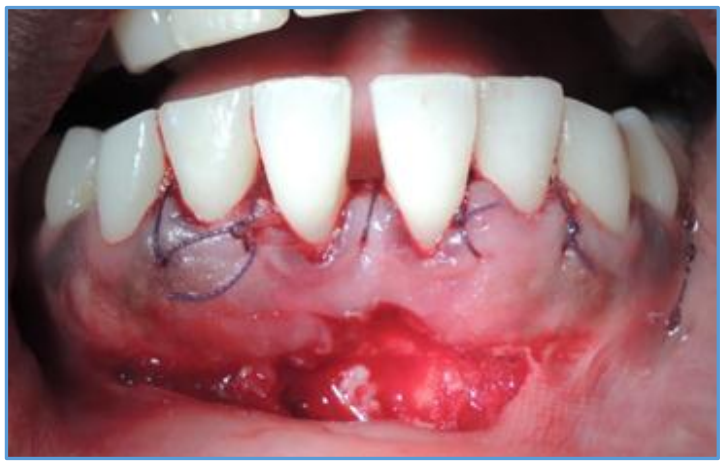

Figure 4. Coronally Positioned Flap Stabilised with Independent Sling Sutures Placed

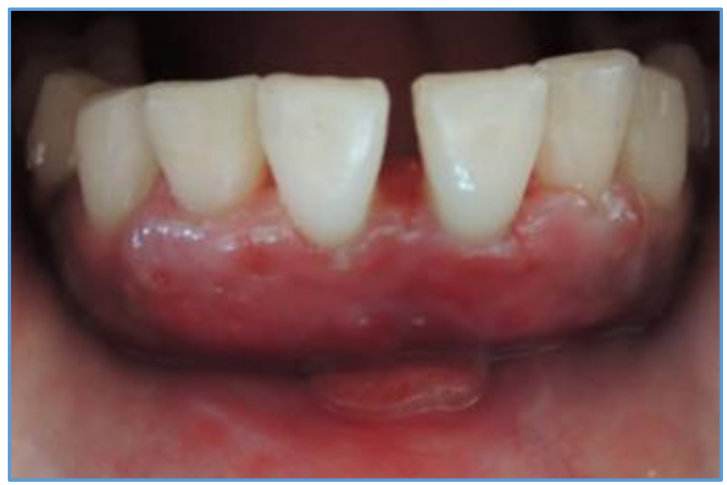

Figure 5. Post-Operative: Increased Width of attached Gingiva with $100 \%$ Root Coverage

Case II

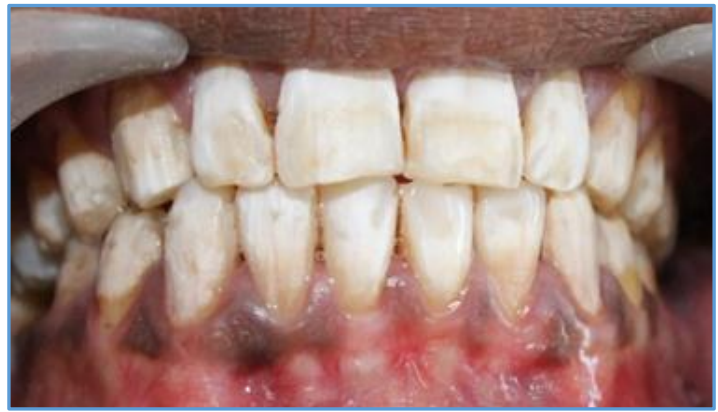

Figure 6. Preoperative Photograph showing Inadequate Width of the attached Gingiva and Miller Class I Recession IRT 31324142

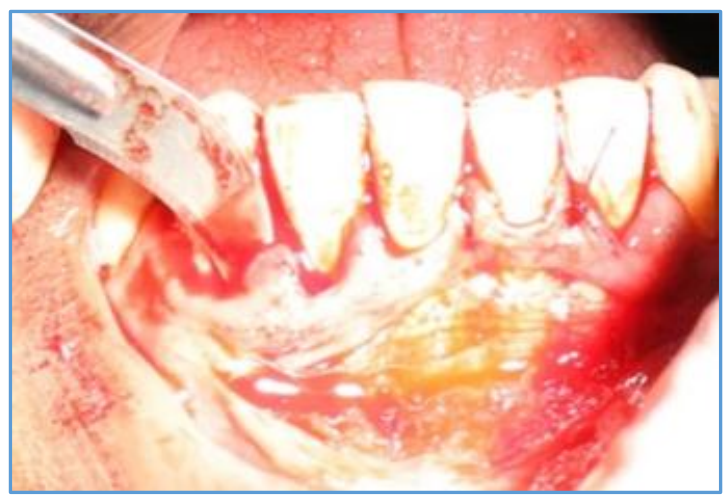

Figure 7. Intraoral Photograph showing Split Thickness Bridge Flap 


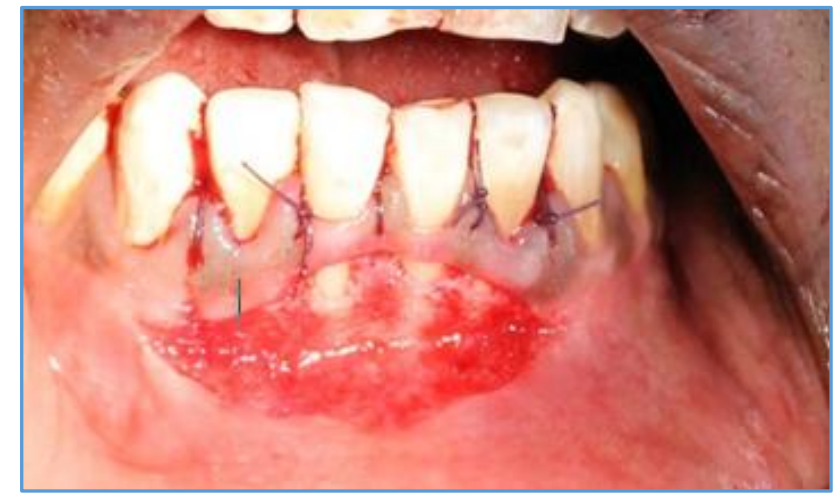

Figure 8. Intra-Operative Photograph showing Arc-Shaped Incision and Bridge Flap Repositioned Coronally with Independent Sling Sutures

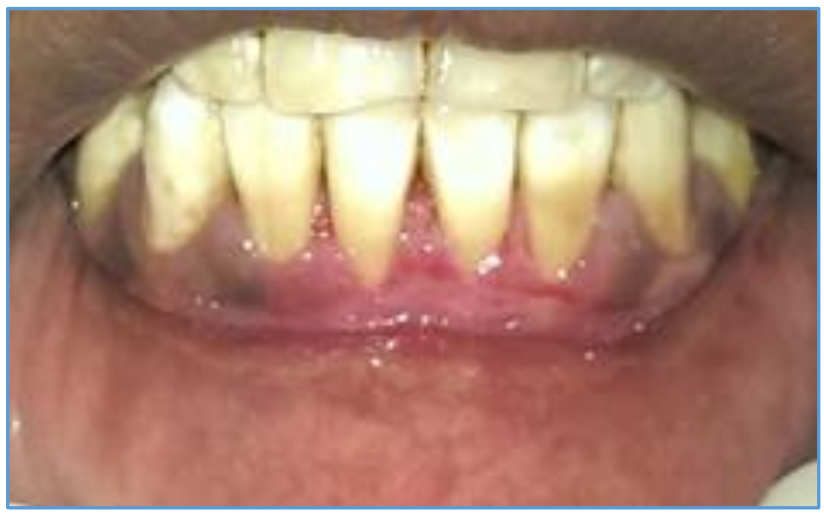

Figure 9. Post-Operative Photograph Marked Increase in the Width of the attached Gingiva can be Appreciated

\begin{tabular}{|c|c|c|c|c|c|c|c|c|}
\hline Case & Age & Gender & $\begin{array}{c}\text { Miller's } \\
\text { Recession }\end{array}$ & $\begin{array}{c}\text { Tooth } \\
\text { Number }\end{array}$ & $\begin{array}{c}\text { GR } \\
(\mathbf{m m})\end{array}$ & $\begin{array}{c}\text { PPD } \\
(\mathbf{m m})\end{array}$ & $\begin{array}{c}\text { CAL } \\
(\mathbf{m m})\end{array}$ & $\begin{array}{c}\text { AG } \\
(\mathbf{m m})\end{array}$ \\
\hline \multirow{2}{*}{1} & \multirow{2}{*}{35} & Female & Class II & 31 & 3 & 2 & 5 & 2 \\
& & & 41 & 4 & 2 & 6 & 2 \\
2 & \multirow{2}{*}{23} & \multirow{2}{*}{ Male } & \multirow{2}{*}{ Class I } & 31,41 & 2 & 1 & 3 & 2 \\
& & & 32,42 & 3 & 2 & 5 & 1.5 \\
\hline \multicolumn{1}{|c|}{ Table 1. Pre-Operative (Baseline Values) } \\
\hline
\end{tabular}

Values are represented as millimetres ( $\mathrm{mm})$.

GR- Gingival Recession, PPD- Probing Pocket Depth, CALClinical Attachment Level, AG- Attached Gingiva.

\begin{tabular}{|c|c|c|c|c|c|c|}
\hline Case & $\begin{array}{c}\text { Miller's } \\
\text { Recession }\end{array}$ & $\begin{array}{c}\text { Tooth } \\
\text { Number }\end{array}$ & $\begin{array}{c}\text { GR } \\
(\mathbf{m m})\end{array}$ & $\begin{array}{c}\text { PPD } \\
\text { (mm) }\end{array}$ & $\begin{array}{c}\text { CAL } \\
\text { (mm) }\end{array}$ & $\begin{array}{c}\text { AG } \\
\text { (mm) }\end{array}$ \\
\hline \multirow{2}{*}{1} & \multirow{2}{*}{ Class II } & 31 & 0 & 1 & 0 & 7 \\
& & 41 & 0 & 2 & 0 & 7 \\
2 & \multirow{2}{*}{ Class I } & 31,41 & 3 & 1 & 4 & 4 \\
\hline \multicolumn{6}{|c|}{ Table 2. Three Months Postoperative Results } \\
\hline
\end{tabular}

Values are represented as millimetres ( $\mathrm{mm})$.

GR- Gingival Recession, PPD- Probing Pocket Depth, CALClinical Attachment Level, AG- Attached Gingiva.

\begin{tabular}{|c|c|c|c|c|c|}
\hline Case & $\begin{array}{c}\text { Miller's } \\
\text { Recession }\end{array}$ & $\begin{array}{c}\text { Tooth } \\
\text { Number }\end{array}$ & $\begin{array}{l}\text { GR Pre- } \\
\text { OP (mm) }\end{array}$ & $\begin{array}{c}\text { GR 3 } \\
\text { Months } \\
\text { (mm) }\end{array}$ & $\begin{array}{c}\text { Root } \\
\text { Coverage } \\
\text { in } \%\end{array}$ \\
\hline \multirow{2}{*}{1} & \multirow{2}{*}{ Class II } & 31 & 3 & 0 & $100 \%$ \\
\hline & & 41 & 4 & 0 & $100 \%$ \\
\hline \multirow{2}{*}{2} & \multirow{2}{*}{ Class I } & 31,41 & 2 & 3 & $-50 \%$ \\
\hline & & 32,42 & 3 & 2 & $66 \%$ \\
\hline
\end{tabular}

Values are represented as millimetres (mm). GR- Gingival Recession.

\begin{tabular}{|c|c|c|c|c|c|}
\hline Case & $\begin{array}{c}\text { Miller's } \\
\text { Recession }\end{array}$ & $\begin{array}{c}\text { Tooth } \\
\text { Number }\end{array}$ & $\begin{array}{c}\text { AG Pre- } \\
\text { oP } \\
\text { (mm) }\end{array}$ & $\begin{array}{c}\text { AG 3 } \\
\text { Months } \\
\text { (mm) }\end{array}$ & $\begin{array}{c}\text { Attached } \\
\text { Gingiva }\end{array}$ \\
\hline \multirow{2}{*}{1} & Class II & 31 & 2 & 7 & $5 \mathrm{~mm}$ \\
& & 41 & 2 & 7 & $5 \mathrm{~mm}$ \\
2 & Class I & 31,41 & 2 & 4 & $3 \mathrm{~mm}$ \\
& 32,42 & 1.5 & 5 & $3.5 \mathrm{~mm}$ \\
\hline \multicolumn{6}{|c|}{ Table 4. Gain in attached Gingiva at 3 Months } \\
Postoperatively \\
\hline
\end{tabular}

Values are represented as millimetres (mm). AG- Attached Gingiva.

\section{RESULTS}

The sutures were removed 10 days after the procedure. The examination of the surgical site revealed uneventful healing without any postoperative complications/ morbidity. Complete root coverage was achieved during the immediate postoperative period in both the cases. In Case 1 these clinical parameters were constant even at 3 months follow-up, whereas in Case 2 there was recession in relation to 31 and 41. In Case 1 hundred percent root coverage was obtained at the end of three months, while in Case 2 where there was postoperative recession in relation to 31 and $41(-50 \%), 66 \%$ root coverage was obtained in relation to 32 and 42 . The maximum gain in the width of the attached gingiva achieved with this procedure was $5 \mathrm{~mm}$ and the minimum gain was 3 $\mathrm{mm}$. The details of the root coverage obtained and gained in the attached gingiva are provided in Tables 2-4.

\section{DISCUSSION OF MANAGEMENT}

Numerous techniques have been addressed for the treatment of gingival recession. The established procedures like the coronally advanced flap, semilunar flap and lateral pedical flap demand an adequate width of attached gingiva, which may not be present always. In such clinical circumstances, a variety of gingival augmentation techniques like the free gingival grafting and connective tissue grafting are performed to increase the width of attached gingiva prior to root coverage procedures.

The original Edlan-Mejchar technique ${ }^{(9)}$ was developed to deepen the vestibule and not to cover gingival recession and it resulted in alveolar bone exposure. Marggraf ${ }^{(8)}$ introduced a surgical procedure for root coverage in case of multiple gingival recessions, namely the double lateral sliding bridge flap technique, which is a combination of Edlan-Mejchar technique and coronally repositioned flap. In this modification the alveolar bone exposure is avoided, thereby allowing uncomplicated and rapid healing in most cases. Additionally, this technique makes it possible to use the coronally repositioned flap (CRF) for root coverage even in 
the situations where the width of the attached gingiva is less than $3 \mathrm{~mm} .{ }^{(10)}$ Hence, the bridge flap technique combines the two procedures together eliminating the need for a separate surgery to increase the width of attached gingiva before root coverage procedures.

The bridge flap technique reduces the incidence of recurrent recession considerably by the simultaneous extension of the vestibule, as the mucosal flap cannot be influenced by muscular tension from an apical direction.(10) The other advantages of bridge flap technique are that by releasing the periosteal fibres, the frenal pull can also be relieved. Therefore, there is no necessity for a separate frenotomy procedure. Also, this technique can be used to cover multiple recessions.

In the present case report, the cases were selected mainly on the patient's chief complaint of aesthetics and hypersensitivity regardless of the aetiology. On close examination, both the cases selected had gingival recession (GR) either because of high frenal pull, shallow vestibule, thin gingival tissue or insufficient width of AG. Miller defined complete root coverage in clinical terms as location of soft tissue margin at the CEJ, presence of clinical attachment to the root, a sulcus depth of $2 \mathrm{~mm}$ or less and absence of bleeding on probing. Appreciable root coverage was achieved in Case 1 as defined by Miller, in spite of narrow width of attached gingiva. The results of the present case series are consistent with the previous studies done by Gupta et al,(6) Romanos et al ${ }^{(9)}$ and Marggraf $(8)$ who found $70 \%$ coverage even after a follow-up period of 5 - 8 years.

In Case 1 , the clinical parameters considered were constant even at 3 months follow-up visit, whereas in Case 2 there was recession in relation to 31 and 41 which could be attributed to the dehiscence and thin gingival biotype. The postoperative aesthetic result was satisfactory in both the patients. Clinical results were favourable at 3 months postoperatively. There was no change in probing pocket depth from baseline value clinically, as the cases selected were already scaled and thoroughly root planed. Some of the methodical aspects recommended by the previous authors were followed in the present procedure in order to achieve successful root coverage. The technical aspects include the initial semilunar incision, which is given at $2 \mathrm{GR}+2$ provided a wide flap ensuing adequate blood supply and root coverage. The interproximal sutures which were placed maintained the flap in a coronal position without tension.[9] Though there was adequate gain in the width of the attached gingiva in both the cases, the recession in Case 2 for 31 and 41 could not be avoided even after carefully fulfilling the afore-mentioned criteria and this could be endorsed to the presence of thin gingival biotype in this patient compared to Case 1 where there was $100 \%$ root coverage obtained. Therefore, the consideration of gingival biotype plays a crucial role for attaining complete root coverage with this procedure.

\section{FINAL CONCLUSION}

Numerous surgical techniques are described in the literature to correct mucogingival deformities. The surgical technique of bridge flap procedure is a reliable solution for attaining root coverage, increasing the width of attached gingiva, deepening the vestibule and simultaneously correcting the problem of high frenum if present in a single step. Future research with larger sample size and long-term follow-up is needed to establish bridge flap as a steadfast treatment modality for root coverage.

\section{REFERENCES}

[1] Roccuzzo M, Bunino M, Needleman I, et al. Periodontal plastic surgery for treatment of localized gingival recessions: a systematic review. J Clin Periodontol 2002;29(Suppl 3):178-94, 195-6.

[2] Allen R. Treating gingival recession. Irish Dent Journal 2011: p. 20-6.

[3] Miller PD. A classification of marginal tissue recession. Int J Periodontics Restorative Dent 1985;5(2):8-13.

[4] Oliver RC, Brown LJ, Leo H. Periodontal diseases in the United States population. J Periodontol 1998;69(2):269-78.

[5] Takei HH, Azzi RR, Han T. Periodontal plastic and esthetic surgery. In: Newmann MG, Takei HH, Klokkevold PR, eds. Carranza's clinical periodontology. $10^{\text {th }}$ edn. St. Louis, Missouri: Saunders/Elsevier 2006: p. 1005-6.

[6] Gupta V, Bains VK, Mohan R, et al. Bridge flap technique as a single-step solution to mucogingival problems: a case series. Contemp Clin Dent 2011;2(2):110-4.

[7] Wade AB. Vestibular deepening by the technique of Edlan and Mejchar. J Periodontal Res 1969;4(4):30013.

[8] Marggraf E. A direct technique with a double lateral bridging flap for coverage of denuded root surface and gingival extension. Clinical evaluation after 2 years. J Clin Periodontol 1985;12(1):69-76.

[9] Romanos GE, Bernumoulin JP, Marggraf E. The double lateral bridging flap for coverage of denuded root surface: longitudinal study and clinical evaluation after 5 to 8 years. J Periodontol 1993;64(8):683-8.

[10] Rajaram V, Uma S, Ravindran SK, et al. Double lateral sliding bridge flap for the coverage of denuded roots: two case reports. Perio 2008;5:29-33. 